\title{
Evaluating Customer Process to Contribute to Customer Acquisition: A Quantitative Study in Jordanian Banking Sector
}

\author{
Samer Alhawari \\ The World Islamic Sciences and Education University, Jordan
}

\begin{abstract}
Over the past few years, banks are increasingly realizing the significance of customers' service; one of the key challenges for them is how to improve the relationship with customers. On any given business day, significant amounts of information fuel business processes that involve parties both inside and outside of enterprise network boundaries. In response, many banks have increasingly recognized the importance of managing customer acquisition from a process approaches' perspective to assure positive impact on customer acquisition.
\end{abstract}

This paper takes on a holistic approach that examines the combined effects of customer processes (Customer Relation, Customer attraction, Customer Knowledge Capture and Customer data Analysis) on customer acquisition. Drawing on this, the framework develops several hypotheses regarding the main interaction effects of customer processes on customer acquisition. Testing of these hypotheses is based on a sample of the data collected from two hundred respondents, drawn randomly from four Jordanian Banks working in the Customer Relationship Management (CRM) area.

The results of the survey show that the four selected factors (Customer Relation, Customer attraction, Customer Knowledge Capture and Customer data Analysis) have a significant impact on customer acquisition. Additionally, the Quantitative evidence from the survey offers further support for this finding. The emerging empirical findings will certainly help both researchers and practitioners in future customer process and Customer acquisition research. The contribution of the paper consists in establishing the need for researching and incorporating customer acquisition process as an important support to keep organizations competitive within the global business environment.

Keywords: Customer relation, Customer attraction, Customer acquisition.

\section{Introduction}

Customer acquisition has emerged as one of the most challenging issues in business because of the value expected from carrying out the customer acquisition in organizations. Customer acquisition has become an important business process because it touches the most important assets of all organizations, which is the customer. Customers nowadays are highly educated, well-aware, more focused and influenced by the global market of the internet (Alryalat et al., 2008).

Certainly, the rapid increasing demands of customers' interacting with organizations are concerned with the acquisition of new customers. Therefore, organizations are starting to think of how to develop their performance. Obviously, this trend is magnified by the rapid development of CRM systems and the adoption of the customer-centric orientation (Stefanou et

Copyright (C) 2012 Samer Alhawari. This is an open access article distributed under the Creative Commons Attribution License unported 3.0, which permits unrestricted use, distribution, and reproduction in any medium, provided that original work is properly cited. Contact author: Samer Alhawari E-mail: Samer.Alhawari@yahoo.com 
al., 2003). In this way, customer acquisition has become a key source for organizations to enhance their competitive advantage. Consequently, they have started to recognize the importance of knowing their customers better to provide online information services due to the rapid change in the business environment, featuring strong competition as a result of the increasing importance of using the Internet to conduct business. They need to connect their database to the Web, which explains the reason why Information Technology (IT)-based CRM systems have been employed in many industry sectors. By realizing that, organizations can create accessible improved knowledge content in the development and provision of products and services to managers on all levels of the firm, achieve shorter new product development cycles, and facilitate and manage organizational innovation and learning (Lancioni and Chandran, 2009). Furthermore, IT is extensively used in this competitive environment to deliver banking services to the consumers (Ganguli and Roy, 2011).

Additionally, Paiva et al. (2002) found that customers' information is the type of information that is most frequently updated, and the company focuses on specific customer information instead of general market information. Unfortunately, many organizations have lost sight of competitive advantage as an effective way to grow and compete with domestic and global competitors. Thus, organizations must gain this customer acquisition from managing relations appropriately.

A large body of work identifying and describing customer acquisition has been conducted, reflecting different viewpoints and issues. These studies have enriched the literature and established a platform for other researchers to continue their quest for widening the scope of the small emerging literature on customer Acquisition (Park and Kim, 2003; Ganapathy et al., 2004; Berndt et al., 2005; Kamakura et al., 2005).

This study seeks to contribute to this field by addressing one of the concerns related to the customer process and customer acquisition and by providing a reliable, confident method of employing the customer acquisition process as a valid model. This implies which customer acquisition process aspects should be focused on, depending on the conceptualized perspective of the customer process and customer acquisition.

As a result, the aim of this paper is to shed light (bring about a better understanding) on establishing long-term relationships with customers by using customer acquisition process in Jordanian Banks to enhance customer acquisition.

This paper is organized as follows. In the next section, a literature review is conducted; section three proposes the research model and hypotheses; section four discusses the research methodology in which a review of the design of the questionnaire, sample, data collection, hypotheses' analysis and results are explored in some depth. The last segment of this paper will review and discuss conclusions.

\section{Literature Review}

\section{CRM Processes}

Over the past three decades, CRM and other ways of systematically managing relationships have developed significantly. However, there is considerable confusion in the academic and managerial literatures about how they differ and what the implications might be of using each approach for effective customer management (Frow et al., 2009). Additionally, CRM has emerged as one of the most demanded issues in business, because of the value expected for carrying out the CRM in organizations. CRM became an important business process,_because it touches the most important assets of all organizations, which is the customer. An early focus in CRM definitions appeared towards IT and its role in gathering and analyzing information about customers in order to identify their needs (Akroush et al., 2011). 
The customer nowadays is highly educated, well-aware, more focused and influenced by the global market of the internet (Alryalat and Alhawari, 2008). Additionally, CRM is based on the premise of integrating people, processes and technology throughout the value chain to understand and deliver customer value better. CRM focuses on maximizing customer satisfaction and retention through building long-term relationships (Kim et al., 2004). Customer relationship marketing techniques focus on single customers and require the organization to be concerned with the customer rather than the product (Chen and Popovich, 2003).

There are some processes of CRM that have appeared in a number of existing process models in CRM. Park and Kim (2003) suggest a framework of dynamic CRM consisting of three stages: The first-stage deals with customer acquisition where an organization recognizes unidentified individuals as customers who might be selected to gather their information through diverse communication channels. The second one is the customer retention stage in which the organization makes equitable relationships through relationship value analysis, so that ordinary customers are turned into core customers who are committed to the relationship with high equity. The final stage is the customer expansion; the main role of this stage is to expand the company's customer base through word-ofmouth marketing and active interactions with the company.

Ganapathy et al. (2004) propose a framework that uses a visualization technology presented in different parts of CRM cycle, which consists of three phases. Firstly, customer attraction happens when customers are attracted to the organization's web site to perform searching and viewing of products. Secondly, customer acquisition takes place when the company attempts to convert individuals to profitable customers. The visualization technology can facilitate the selection and evaluation of the products and services. Finally, customer analysis is used to analyze the different customer data in order to develop better understanding of customer behavior and pattern.

Another study by Berndt et al. (2005) explains the implementation of CRM phase, which is composed of three processes: acquisition, retention and profitability. Acquisition of customers refers to the need of organizations to find new customers for their Products- this means they are required to develop strategies to attract potential customers. Retention of customers denotes focusing on existing customers in order to ensure that they continue purchasing and continue supporting the product. Profitability refers to the lifetime value of the customer to the organization, taking into account the income and expenses associated with each customer and their respective transactions over time.

Additionally, Kamakura et al. (2005) explain that CRM research can be organized along the customer life cycle including three phases. Firstly, Customer Acquisition: aims to obtain more, profitable customers. Secondly, Customer Development: describes the growth of revenues from existing customers. Finally, Customer retention: refers to significant impact on firm profitability. A focus on customer retention implies that firms need to understand the determinants of customer defection and to predict those customers who are at risk of defection at a particular point in time. Finally, Alryalat and Alhawari (2008) stated that CRM process can be planned along the customer life cycle including three phases. Firstly, a process about customer: with the objective to attain Customer Acquisition. Secondly, a process for customer: with its objective to customer retention. Finally, process from Customer: refers to significant impact on Customer Expansion.

To summarize all CRM theories above, the purpose of the research is to contribute to this area by looking at present at the taxonomy of CRM process as shown in Table 1. 
Table 1. Taxonomy of CRM Process

\begin{tabular}{|l|l|c|}
\hline \multicolumn{1}{|c|}{ Main } & \multicolumn{1}{|c|}{$\begin{array}{c}\text { Sub dimension/ } \\
\text { Description of Process }\end{array}$} & References \\
\hline CRM processes & $\begin{array}{l}\text { Customer Acquisition } \\
\text { Customer Retention } \\
\text { Customer Expansion }\end{array}$ & $\begin{array}{c}\text { Park and Kim } \\
(2003)\end{array}$ \\
\hline CRM processes & $\begin{array}{l}\text { Customer Attraction } \\
\text { Customer Acquisition } \\
\text { Customer Analysis }\end{array}$ & $\begin{array}{c}\text { Ganapathy et al. } \\
(2004)\end{array}$ \\
\hline CRM processes & $\begin{array}{l}\text { Customer Acquisition } \\
\text { Customer Retention } \\
\text { Customer Profitability }\end{array}$ & $\begin{array}{c}\text { Berndt et al. } \\
(2005)\end{array}$ \\
\hline CRM processes & $\begin{array}{l}\text { Customer Acquisition } \\
\text { Customer Development } \\
\text { Customer Retention }\end{array}$ & $\begin{array}{c}\text { Kamakura et al. } \\
(2005)\end{array}$ \\
\hline CRM processes & $\begin{array}{l}\text { Process about customer } \\
\text { Process for customer } \\
\text { Process from customer }\end{array}$ & Alryalat and \\
& \multicolumn{2}{|l}{} \\
\hline
\end{tabular}

\section{Concept of Customer Acquisition}

Due to strong competition, current economic crisis and rapid changes in the business environment, organizations started seeking improvement in their business processes to reduce the cost, improve efficiency and reduce the impact of the economic crisis on their functionality (Nehari-Talet et al., 2010). Since the 1990s, organizations realized that knowledge could be about diverse organizational aspects, such as products, processes, customers, employees, partners, competitors and good and bad experiences.. Many organizations started since then to pay attention to managing this knowledge until it became a hot topic nowadays as many business communities are trying to properly understand and implement it (Jennex, 2007).

Additionally, customer acquisition is about defining the needs that have to be fulfilled in order to gain new customers. Customer Acquisition focuses on using different available techniques to establish a new relationship with prospect customers. It builds up its major efforts on employing different marketing communication tools that can help in the process of acquiring new customers to the company. Furthermore, Customer Acquisition is important where the organization recognizes unidentified consumers as customers who are identifiable by gathering information about them through diverse communication channels (Park and Kim, 2003).

Also, a customer acquisition objective is to obtain more profitable prospective customers. For example, new home buyers are targeted for home insurance. In spite of its importance, identifying potential customers for acquisition is an area of negligible attention (Kamakura et al., 2005). Additionally, Customer Acquisition is essential where a company attempts to convert customers into profitable ones (Ganapathy et al., 2004). Moreover, acquisition of customers refers to the need of organizations to find new customers for their Products; this means they are required to develop strategies to attract potential customers (Berndt et al., 2005). Chaffey (2004) presents a three-stage model of CRM which shows how customer relationships can be managed. His model proposes that customers are first acquired via clear communication of a powerful value proposition. They are retained via a good service, and the relationship is extended via the delivery of tailored products/services to clearly defined customer segments (Chaffey, 2004). 


\section{Process of Customer Acquisition}

Organizations are forced to compete based on customer acquisition. In this knowledgebased era, organizations can expand and sustain a competitive advantage through initiation of accurately developed customer acquisition. To achieve the process concerning customer acquisition, four substages have to be taken into account as shown in Table 2.

Table 2. Taxonomy of Process Customer Acquisition

\begin{tabular}{|c|l|l|}
\hline $\begin{array}{c}\text { Main } \\
\text { dimension/ } \\
\begin{array}{c}\text { Customer } \\
\text { Acquisition }\end{array}\end{array}$ & \multicolumn{1}{|c|}{$\begin{array}{c}\text { Sub dimension/ } \\
\text { parts of process }\end{array}$} \\
\hline $\begin{array}{c}\text { Customer } \\
\text { Acquisition } \\
\text { Process }\end{array}$ & Customer Relation & $\begin{array}{l}\text { References } \\
\text { Alryalat and Alhawari (2008) } \\
\text { Winer (2001) } \\
\text { Ganapathy et al. (2004) } \\
\text { Body and limayem (2004) } \\
\text { Parikh (2001) } \\
\text { Deng and Yu (2006) } \\
\text { Bouthillier and Shearer (2002) } \\
\text { Winer (2001) } \\
\text { Ganapathy et al. (2004) }\end{array}$ \\
\hline
\end{tabular}

The first phase is customer relation, which determines how organizations deal with customers at the present time. Furthermore, the objective of this phase is to seek the most preferable methods to be used with customers. The processes of acquiring customers are of prime value for organizations. Many organizations fail because there is no clear strategy as to dealing with customers and specifically the process of acquiring customers (Alryalat and Alhawari, 2008). Also, the customer relation delineates the current association between the company and its customers. It portrays the existing services offered by the company to its customers.

The second stage is about "customer attraction", which refers to a set of activities and methods employed to gain the attentions of promising customers and converting these attentions to accomplishment. Also, the organization utilizes several characteristics that are required in the process of attracting customers. These characteristics should include certain data consisting of personal and supplementary data known as profiling. Additionally, targeting the customers refers to Mass Marketing approaches, such as television, radio, or print advertising as being useful for generating awareness and achieving other communications objectives (Winer, 2001). Moreover, customer attraction occurs when the customers are attracted to the organization's web site to search and view products (Ganapathy et al., 2004). Therefore, understanding customers' expectations is vital in identifying customers' desires and supplying those customers with the products and services that meet their expectations.

The third stage is "customer-knowledge capture", where knowledge acquisition is an activity that deals with finding and acquiring knowledge from its various resources. In this stage, organizations need to make a conscious effort to sense, search and define relevant knowledge to capture (Parikh, 2001). Also, Bouthillier and Shearer (2002) described the acquisition process as that which makes bringing the knowledge from external sources into an organization possible. It collects and represents knowledge in a form that can be used by a computer (Deng and Yu, 2006).

The fourth stage is about "analyzing customer data" accumulated from different sources. It emphasizes on studying the 
customers' behaviors, attractions and interests. The analysis utilizes various available sources to gain customers' data by means of offering initiatives and free access. The analysis phase relies on the quality of data collected and completed. Additionally, customer databases have been analyzed with the intent to define customer segments. There are several varieties of multivariate statistical methods such as a cluster (Winer, 2001). Therefore, customer analysis is used to analyze the different customer data in order to develop better understanding of customer activities and patterns (Ganapathy et al., 2004).

Based on the preceding discussion, it must be asked: Is the process of customer acquisition as proposed and developed in Jordanian banks reliable and valid? To fill in the existing gap in the literature, this study examines the applicability of the customer process construct in an emerging economy context on customer acquisition.

\section{Research Model and Hypothesis}

Conceptually, the customer process and customer acquisition has been widely embraced by businesses. Many organizations have initiated models to improve customer acquisition. As stated above, customer process has become the focal point within today's competitive markets. Thus, the process of acquiring customers is a prime value for organizations. Many organizations fail, because there is no clear strategy for dealing with customers, and specifically for the process of acquiring customers. Then, customer acquisition is vital as the first stage of the CRM process. Successful organizations depend on customer acquisition as the way to ensure their survival in today's knowledge savvy and competitive marketplace environment.

In this regard, the first phase of CRM begins with the process about customer as an idiom which refers to the understanding of how to acquire customers (Alryalat and Alhawari, 2008).

Organizations can expand and sustain a competitive advantage through initiation of accurately developed Customer Acquisition process. Additionally, there are three phases involved in the CRM process model in order to improve customer satisfaction. These are the phases that begin with acquiring, retaining and expanding of customer relation (Alryalat and Alhawari, 2008).The CRM process includes the three main phases that deal with the Process about Customer to acquire new customer, Process for Customer to retain existing customer, and Process from Customer to expand the relationship with customer (Alryalat and Alhawari, 2008).

Lately, Alryalat and Alhawari (2008) have explained that the first phase of CRM is called Process about Customers; a concept that refers to the effort of acquiring customers which includes four important stages.

The first sub stage is concerned with "Customer Relation" which can be defined as the relationship or bond that binds the customer closely with the company.

Additionally, the second sub-stage concerns with "Customer Attraction ", which requires forming an outline of the actions and procedures needed to achieve the company objectives. Also, "Customer Knowledge Capture" needs to clear steps and procedures to capture the customer knowledge. Finally, it needs to analyze customer data from the different sources.

Based on the theoretical background and literature review, a conceptual model was developed to examine the role of Customer process (Customer Relation, Customer Attraction, Customer Knowledge Capture and Customer Data Analysis) and on Customer Acquisition. Figure 1 presents the research model. 


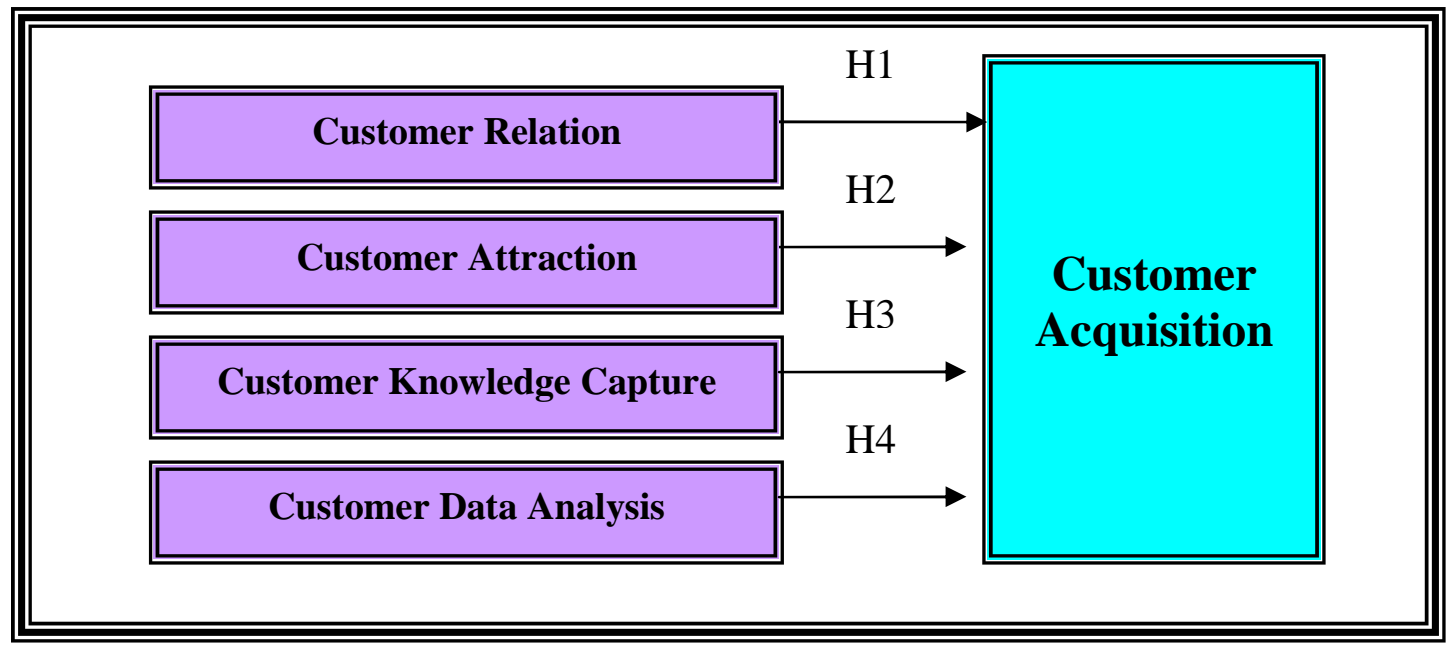

Figure 1. Relationship between Customer Process and Customer Acquisition

Four hypotheses address the associations between customer process and customer acquisition. The four hypotheses which guide this line of inquiry are as follows:

- H1: There is direct positive relationship between Ccustomer Relation and Customer Acquisition.

- H2: There is direct positive relationship between Customer Attraction and Customer Acquisition.

- H3: There is direct positive relationship between Customer Knowledge Capture and Customer Acquisition.

- H4: There is direct positive relationship between Customer Data Analysis and Customer Acquisition.

\section{Research Methodology}

To ensure the reliability and validity of the questionnaire, several criteria have been considered when designing a questionnaire survey. A pilot test was conducted on the practitioners from the selected banks to reduce and minimize any misunderstanding or ambiguous questions and procedures that would be used in conducting the survey. This selection helps to give the best feedback about the content of the questionnaire and research.
The questionnaire started with a brief description of the meaning of the main concepts, and it gave instructions on how to answer each section of the questionnaire. An initial draft was developed based on an extensive literature review. It includes many questions which are in line with the research aims. For that reason, the research survey could be described as being comprehensive. It is divided into two parts. The first part includes the personal information of the respondents such as age, gender, area of profession and years of experience. The second part includes the questions related to variables that affect the integrated customer process regarding customer acquisition. See appendix 1 .

\section{Sample}

The sample of the survey is divided into four Jordanian Bank which apply the CRM system. A total of 215 questionnaires were sent. A total of 206 questionnaires were returned, 200 of which were completed and 6 were uncompleted. A total of nine questionnaires were not returned. To increase the return rate, each company was assigned a contact person to collect and return the questionnaires. Table 3 shows the summary of the sample size. 
Table3. Summary of the Sample Size

\begin{tabular}{|l|c|c|c|c|}
\hline Category & $\begin{array}{c}\text { Number of } \\
\text { Questionnaire } \\
\text { Distributed }\end{array}$ & $\begin{array}{c}\text { Number of } \\
\text { Completed } \\
\text { Questionnaires } \\
\text { Returned }\end{array}$ & $\begin{array}{c}\text { Number of } \\
\text { Uncompleted } \\
\text { Questionnaires } \\
\text { Returned }\end{array}$ & $\begin{array}{c}\text { Number of } \\
\text { Questionnaires } \\
\text { Unreturned }\end{array}$ \\
\hline Bank 1 & 70 & 65 & 2 & 3 \\
Bank 2 & 45 & 42 & 1 & 2 \\
Bank3 & 45 & 44 & 1 & 0 \\
Bank 4 & 55 & 49 & 2 & 4 \\
Total & $\mathbf{2 1 5}$ & $\mathbf{2 0 0}$ & $\mathbf{6}$ & $\mathbf{9}$ \\
\hline
\end{tabular}

\section{Data Collection}

The structural questionnaire design was applied to develop the survey instrument. Each was operationalized on a five point Likert-type scale where $\mathbf{1}=$ "strongly agree" and $\mathbf{5}$ = "strongly disagree". In order to ensure the variables selected for this study are relevant to the respondents, a pilot study was conducted to increase the validity and reliability of the questionnaire. Experts were invited to review the questionnaire and pilot tests were administered before designing the final questionnaire. Ultimately, this pilot study helped to identify the participants' opinion and experiences.

This study relied on a quantitative approach of collecting information from the respondents. The research focused on how the bank understands and views the purpose and importance of the customer process to enhance customer acquisition based on their experience. The quantitative approach supplied a suitable research data collection strategy, allowing the collection of a large amount of data from a sizeable population in a highly economical way. The factor analysis was adopted to test construct validity to determine the relationships between variables.

The construct was subjected to a scale reliability procedure of SPSS 11.0, by using the Cronbach's Alpha (1951) criterion to assess the internal consistency of the studied construct. The Cronbach's Alpha coefficient is above 0.75 ; the value exceeds the accepted cut-off value of 0.70 , as suggested by Nunnally (1978). This indicates that each individual item is internally consistent and highly reliable.

\section{Data Analysis and Result}

This study contains 159 males with a percentage of $79.5 \%$ and 41 females with a percentage of $20.5 \%$. The majority of respondents (102 or $51 \%)$ indicates that their area of specialization Information Technology (IT). The smallest group area of specialization of respondents indicated Business Management (8 or 4\%).

Additionally, the majority of respondents (112or 56. \%) indicated that their Company Size was small organization. The smallest group Company Size of respondents indicated medium organization (69 or $35.5 \%$ ). Also, the majority of respondents (73 or 36.5\%) noted that their years of experience range from 1 to 2 years. While the smallest group of respondents (Less than 1year or $34 \%$ ) said their years of experience are less than 1 year. This demographic data is detailed in Table 4. 
Table 4. Demographic Data

\begin{tabular}{|l|l|c|c|}
\hline Description & \multicolumn{1}{|c|}{ Variable } & Result & Percentage \\
\hline Gender & Male & 159 & $79.5 \%$ \\
& Female & 41 & $20.5 \%$ \\
Area of & Information Technology & 102 & $51 \%$ \\
specialization & Business Management & 8 & $40 \%$ \\
& Customer Relationship & 28 & $14 \%$ \\
& Management & & \\
& Other & 62 & $31 \%$ \\
& Less than 1year & 34 & $17 \%$ \\
Experience & $1-2$ years & 73 & $36 \%$ \\
& 3-5 years & 52 & $20.5 \%$ \\
& 6years or more & 112 & $56 \%$ \\
\multirow{5}{*}{ Company Size } & Small & 69 & $35.5 \%$ \\
& Medium & 19 & $9.5 \%$ \\
\hline
\end{tabular}

Based on the objectives and hypotheses of the study, the researchers applied the Analysis (ANOVA). Tables 5, 6, 7 and 8 represent the test of the hypotheses by using analysis of variance (ANOVA), based on the significant level of $(0.05)$.

Table 5. ANOVA Test for Customer Relation and Customer Acquisition

\begin{tabular}{|l|l|l|l|l|}
\hline $\mathbf{R}$ & R Square & Adjusted R Square & F & Sig. \\
\hline 0.17 & 0.03 & 0.02 & 6.04 & 0.01 \\
\hline
\end{tabular}

Referring to Table 5, 3\% of the variance in Customer Acquisition is accounted by Customer Relation, the $\mathrm{F}$ value is 6.04 with a significance 0.01 , which is less than (0.05). For that reason, there is an effect of Customer Relation on Customer Acquisition. In testing the hypotheses pertinent to Customer Relation and Customer Acquisition, the phases of Customer Relation were recommended by Ganapathy et al. (2004) and more recently in Alryalat and Alhawari (2008). Furthermore, previous research has suggested the main effect of Customer Relation on customer Acquisition (e.g. Ganapathy et al. (2004); Alryalat and
Alhawari (2008). Therefore, previous research has generally noted a significant positive effect of "Customer Relation", and the present study confirms this finding, on customer Acquisition. In contrast, previous research has provided limited empirical insight into the impact of "Customer Relation" on customer Acquisition. The present results confirm the expected positive effect of "Customer Relation" on customer Acquisition. The implication of this finding for Jordanian Bank is that they may need to pursue a combined strategy aimed at managing "Customer Relation" and customer Acquisition to enhance the competitive advantage.

Table 6. ANOVA Test for Customer Attraction and Customer Acquisition

\begin{tabular}{|l|l|l|l|l|}
\hline $\mathbf{R}$ & R Square & Adjusted R Square & F & Sig. \\
\hline 0.18 & 0.03 & 0.03 & 6.99 & 0.00 \\
\hline
\end{tabular}

In Table 6, 3\% of the variance in Customer Acquisition is accounted by Customer Attraction; the $F$ value is 6.99 with a significance equal 0.00 , which is less than 0.05 . For this reason, there is an effect of Customer Attraction on Customer 
Acquisition. In testing the hypotheses relating to the Customer Attraction and Customer Acquisition; the phases were recommended by Winer (2001) and more recently by Alryalat and Alhawari (2008). Furthermore, previous research has suggested the main effect of Customer Attraction on customer Acquisition (e.g. Ganapathy et al., (2004); Body and limayem, 2004). Therefore, previous research has generally noted a significant positive effect of Customer Attraction on customer Acquisition, a finding which the present study confirms. In contrast, previous research has provided limited empirical insight into the impact of "Customer Attraction" on customer Acquisition. This paper's results confirm the expected positive effect of "Customer Attraction" on customer Acquisition. The implication of this finding for Jordanian Bank is that they may need to pursue a combined strategy aimed at managing "Customer Attraction" and customer Acquisition to enhance the competitive advantage.

Table 7. ANOVA Test for Customer Knowledge Capture and Customer Acquisition

\begin{tabular}{|l|l|l|l||l|}
\hline $\mathbf{R}$ & R Square & Adjusted R Square & F & Sig. \\
\hline 0.21 & 0.04 & 0.04 & 9.76 & 0.00 \\
\hline
\end{tabular}

From Table 7, 4\% of the variance in Customer Acquisition accounted by Customer Knowledge Capture; the F value is 9.76 with a significance equal 0.00 , which is less than (0.05). For that reason, there is an effect of Customer Knowledge Capture on Customer Acquisition. In testing the hypotheses relating to the "Customer Knowledge Capture" and Customer Acquisition, the phases were recommended by Parikh (2001) and more recently by Alryalat and Alhawari (2008). Furthermore, previous research has suggested the main effect of "Customer Knowledge Capture" on customer Acquisition (e.g. Deng and Yu, 2006; Bouthillier and Shearer, 2002). Therefore, previous research has generally noted a significant positive effect of "Customer Knowledge Capture", and this study confirms this finding, on customer Acquisition. In contrast, previous research has provided limited empirical insight into the impact of "Customer Knowledge Capture" on customer Acquisition. The herein results confirm the expected positive effect of "Customer Knowledge Capture" on customer Acquisition. The implication of this finding for Jordanian Bank is that they may need to pursue a combined strategy aimed at managing "Customer Knowledge Capture" and customer Acquisition to enhance the competitive advantage.

Table 8. ANOVA Test for Customer Data Analysis and Customer Acquisition

\begin{tabular}{|l|l|l|l|l|}
\hline R & R Square & Adjusted R Square & F & Sig. \\
\hline 0.22 & 0.04 & 0.04 & 10.1 & 0.00 \\
\hline
\end{tabular}

From Table 8, 4\% of the variance in Customer Acquisition is accounted by Customer Analysis, the F value is 10.1 with a significance equal 0.00 , which is less than 0.05 . For that reason, there is an effect of Customer Analysis on Customer Acquisition. In testing the hypotheses relating to the Customer data analysis and Customer Acquisition, the phases were recommended by Winer (2001) and more recently by Alryalat and Alhawari (2008). Furthermore, previous research has suggested the main effect of "Customer data analysis" on customer Acquisition (e.g. Ganapathy et al, 2004). Therefore, previous research has generally noted a significant positive effect of "Customer data analysis", and the present study confirms this finding, on customer Acquisition. In contrast, previous research has provided limited 
empirical insight into the impact of Customer data analysis on Customer Acquisition. Our results confirm the expected positive effect of Customer data analysis on Customer Acquisition. The implication of this finding for Jordanian Bank is that they may need to pursue a combined strategy aimed at managing Customer data analysis and Customer Acquisition to enhance the competitive advantage.

The relation between the customer processes and customer acquisition was confirmed in this study and the findings are summarized as follows:

1) Customer relation has a positive impact on customer acquisition.

2) Customer attraction has a positive impact on customer acquisition.

3) Customer knowledge capture has a positive impact on customer acquisition.

4) Customer data analysis has a positive impact on customer acquisition.

\section{Conclusion}

\section{Discussions of the Study and Practical Implication}

This study represents an attempt to construct an integrated customer process with practical advice as to how banks can build and sustain their competitiveness in an increasingly competitive sector such as theirs, in view of the increasing competition and pursuit of customer acquisition that requires more services banks to focus on certain core processes in order to deliver better value to acquire more customers. In this context, the enterprise's information system can be among its most valuable assets. Therefore, the paper aims to build a more complete framework of the factors that influence Customer Acquisition.

The results of this study clearly show that four of the selected determinants (Customer Relation, Customer attraction, Customer Knowledge Capture and
Customer Analysis) solutions offer a multifaceted capability to significantly increase an enterprise's ability to manage Customer Acquisition amongst Jordanian banks. However, these solutions are prone to disrupt or influence other processes and the organizational culture if improperly or hurriedly implemented. The paper has illustrated the role that customer processes can achieves in Customer Acquisition, therefore helping to acquire customers by providing the members of the organization with real information enabling correct reaction in making the right decisions in order to gain the competitive advantage.

This research contributes to further understanding of the Customer processes and Customer Acquisition in the literature. It describes an integration of customer processes and Customer Acquisition. The authors hope that these findings will shed some light for policy makers allowing them to integrate customer processes and Customer Acquisition to improve customer satisfaction in Jordanian banks. To the best of the author's knowledge, no existing studies have empirically tested for an interaction effect on acquisition of customer and CRM processes. Similarly, while the interaction effect between CRM processes has been suggested as phases, empirical support is scant. This study fills these two major gaps in the literature.

The banks should be aware of the use of these practices in an integrated manner towards the realization of organizational objectives and higher understanding of Customer Acquisition. Managers should be well aware that a changed paradigm of in people management is essential in changing business environment. The focus of this new approach should be to attract and retain the talents and leverage the talent to achieve competitive advantage through a proactive Customer process leading to customer Acquisition. It is imperative for managers to fully understand the strategic pay-off of the investment made in training and development of in customer Acquisition. This investment should aim at constantly improving competency levels of the workforce. 
This study can serve as an attempt to provide a customer process with practical advice as to how banks can build and sustain their competitiveness, which is the competition and Customer Acquisition that requires more services to focus on certain core processes in order to deliver better value to their customers to acquire more customers. In this regard, an enterprise's information can be among its most valuable assets. Therefore, the paper attempts to build a more complete framework of the factors that influence customer Acquisition.

\section{Limitations and Future Study}

Notwithstanding the above, this study has some limitations that offer opportunities for future research. It is recognized that this study is only a first step towards a constructing a theoretical and practical framework in the area of CRM and customer Acquisition. To accomplish the authors' ultimate objective, they have to overcome several critical limitations, which should be addressed in future studies. Firstly, the results cannot be generalized since the study is done in a Jordanian cultural context. Secondly, this research has been undertaken in Jordanian banks; hence in a particular context Jordanian banks and customer Acquisition success are measured using the dimensions of impact on business processes, strategy, leadership, efficiency and effectiveness of CRM processes, efficiency and effectiveness of the CRM system, organizational culture and knowledge content. For the benefits of the research, this study should be conducted in a different country while using large banks for sampling purposes. The paper has also revealed a considerable number of interesting issues that would require future study such as: future research would aim to retain and enhance the predictive power of the conceptual model proposed in this research. One major direction for further research could be geared towards reproducing this study across a broader range of other countries in high size organizations for comparative purposes.

\section{References}

Akroush, M. N., Dahiyat, S. E., Gharaibeh, H. S. \& Abu-Lail, B. N. (2011). "Customer Relationship Management Implementation an Investigation of a Scale's Generalizability and its Relationship with Business Performance in a Developing Country Context," International Journal of Commerce and Management, 21 (2),158191.

Alryalat, H. \& Al Hawari, S. (2008). "Towards Customer Knowledge Relationship Management: Integrating Knowledge Management and Customer Relationship Management process," Journal of Information and Knowledge Management, 7 (3), 145-157.

Bernard, H. R. (1988). Research Methods in Cultural Anthropology, Newbury Park, CA: Sage.

Berndt, A., Herbst, F. \& Lindie, R. (2005). "Implementing a Customer Relationship Management Program in an Emerging Market," Journal of Global Business and Technology, 1 (2), 81-89.

Bibiano, L. H. \& Pastor, J. A. (2006). 'Towards a Definition of a CRM System Life-Cycle,' In Proceedings European and Mediterranean Conference on Information Systems (EMCIS), Costa Blanca, Alicante, Spain.

Body, A. L. \& Limayem, M. (2004). "The Impact of Customer Relationship Management on Customer Loyalty: The Moderating Role of Web Site Characteristics," Journal of Computer Mediated Communication, 9 (3).

Bouthillier, F. \& Shearer, K. (2002). "Understanding Knowledge Management and Information Management: The Need for an Empirical Perspective," Information Research Journal, 8 (1), 1-39.

Chaffey, D. (2004). E-Business and ECommerce Management (Second Edition), London, FT Prentice Hall. 
Chen, I. J. \& Popovich, K. (2003). "Understanding Customer Relationship Management (CRM) People, Process and Technology," Business Process Management Journal, 9 (5), 672-688.

Cronbach, L. J. (1951). "Coefficient Alpha and the Internal Structure of Tests," Psychometrika, (16), 297-333.

Frow, P., Payne, A., Wilkinson, I. F. \& Young, L. (2009). "Customer Management and CRM: Addressing the Dark Side," Journal of Services Marketing, 25 (2), 79-89.

Ganapathy, S., Ranganathan, C. \& Sankaranarayanan, B. (2004). "Visualization Strategies and Tools for Enhancing Customer Relationship Management," Communication of the ACM, 47 (11), 92-97.

Ganguli, S. \& Roy, S. K. (2011). "Generic Technology-Based Service Quality Dimensions in Banking Impact on Customer Satisfaction and Loyalty," International Journal of Bank Marketing, 29 (2), 168-189.

Kamakura, W., Mela, C. F., Ansari, A., Bodapati, A., Fader, P., Iyengar, R., Naik, P., Neslin, S., Sun, B. \& Verhoef, P. C. (2005). "Choice Models and Customer Relationship Management," Marketing Letters, 16 (3), 279-291.

Kim, J. W., Choi, J., Qualls, W. \& Park, J. (2004). 'The Impact of CRM on Firm-and Relationship Level Performance in Distribution Network,' Communications of the Association for Information Systems, (14), 632-652.

Lancioni, R. A. \& Chandran, R. (2009). "Managing Knowledge in Industrial Markets: New Dimensions and Challenges," Industrial Marketing Management, 38 (2) P. 148.
Nehari-Talet, A., Alhawari, S. \& Alryala, H. (2010). "The Outcome of Knowledge Process for Customer of Jordanian Companies on the Achievement of Customer Knowledge Retention," International Journal of Knowledge Management, 6 (1),44-61.

Nunnally, J. C. (1978). Psychometric Theory, 2nd Ed, New York: Mcgraw-Hill.

Paiva, E. L., Roth, A. V. \& Fensterseifer, J. E. (2002). "Focusing Information in Manufacturing: A Knowledge Management Perspective," Industrial Management and Data Systems, 102(7), 381-9.

Parikh, M. (2001). "Knowledge Management Framework for High Tech Research and Development," Engineering Management Journal, 13 (3), 27-34.

Park, C.- H. \& Kim, Y.- G. (2003). "A Framework of Dynamic CRM: Linking Marketing with Information Strategy," Business Process Management Journal, 9 (5), 652-671.

Qianwang, D. \& Dejie, Y. (2006). 'An Approach to Integrating Knowledge Management into the Product Development Process,' Journal of Knowledge Management Practice, 7(2).

Stefanou, C. J., Sarmaniotis, C. \& Stafyla, A. (2003). "CRM and Customer-Centric Knowledge Management: An Empirical Research," Business Process Management Journal, 9 (5), 617-634.

Winer, R. S. (2001). "A Framework for Customer Relationship Management," California Management Review, 43 (4), 89105. 


\section{Appendix.1}

Questionnaire: Integrating Customer Process and Customer Acquisition

\section{The Aim of Questionnaire}

The aim of the questionnaire is to integrate Customer Process with Customer Acquisition. Your answers to the questions below are highly appreciated and all

\section{Part One: Personal Information}

\section{Gender}

\begin{tabular}{|l|l|}
\hline Male & $\square$ \\
\hline Female & $\square$ \\
\hline
\end{tabular}

\section{Area of specialization}

\begin{tabular}{|l|l|}
\hline Information Technology & $\square$ \\
\hline Business Management & 0 \\
\hline Customer Relationship Management & $\square$ \\
\hline other & $\square$ \\
\hline
\end{tabular}

\section{How many years in professional life?}

\begin{tabular}{|l|l|}
\hline Less than 1 year & $\square$ \\
\hline 1-2 years & 0 \\
\hline 3-5 years & $\square$ \\
\hline 6 years or more & $\square$ \\
\hline
\end{tabular}

\section{Company Size}

\begin{tabular}{|l|l|}
\hline Small & 0 \\
\hline Medium & 0 \\
\hline Large & 0 \\
\hline
\end{tabular}

information provided will be dealt with confidentially. The intention of the questionnaires below is intended for research purposes only.

Note: The questions below are divided into two parts. Part One contains personal information and Part Two includes questions related to Customer Process_and Customer Acquisition. Please answer both parts. 


\section{Part Two: Information on Relationship between Customer Process and Customer Acquisition.}

\begin{tabular}{|c|c|c|c|c|c|}
\hline Questions & $\begin{array}{l}\text { Strongly } \\
\text { Agree }\end{array}$ & Agree & Neutral & Disagree & $\begin{array}{l}\text { Strongly } \\
\text { Disagree }\end{array}$ \\
\hline 1. Your organization has a clear customer relation & & & & & \\
\hline $\begin{array}{l}\text { 2. Your organization views its customer relation } \\
\text { as communication to describe the objectives }\end{array}$ & & & & & \\
\hline $\begin{array}{l}\text { 3. Customer relation supports describing the } \\
\text { current relationship between your organization } \\
\text { and the customers }\end{array}$ & & & & & \\
\hline $\begin{array}{l}\text { 4. Customer relation is an important way to } \\
\text { establish a successful relationship with the } \\
\text { customers }\end{array}$ & & & & & \\
\hline $\begin{array}{l}\text { 5. Company uses any basic information about the } \\
\text { customers in order to attract them. }\end{array}$ & & & & & \\
\hline $\begin{array}{l}\text { 6. Company utilizes different tools to attract the } \\
\text { customers }\end{array}$ & & & & & \\
\hline $\begin{array}{l}\text { 7. Selecting a new customer is considered an } \\
\text { important part of attraction }\end{array}$ & & & & & \\
\hline $\begin{array}{l}\text { 8. the quality of data existing has an impact on } \\
\text { the attracted customer }\end{array}$ & & & & & \\
\hline $\begin{array}{l}\text { 9. Customer Knowledge Capture helps in } \\
\text { understanding how to capture the knowledge } \\
\text { needed }\end{array}$ & & & & & \\
\hline $\begin{array}{l}\text { 10.Customer Knowledge Capture needs to } \\
\text { determine the source of Customer knowledge }\end{array}$ & & & & & \\
\hline $\begin{array}{l}\text { 11. Customer Knowledge Capture is essential to } \\
\text { test the reliability and correctness of Customer } \\
\text { knowledge for further processing }\end{array}$ & & & & & \\
\hline $\begin{array}{l}\text { 12. Customer Knowledge Capture stage focuses } \\
\text { on capturing Customer knowledge existing } \\
\text { within the customers }\end{array}$ & & & & & \\
\hline $\begin{array}{l}\text { 13. The quality of data completeness has an } \\
\text { impact on the analysis phase }\end{array}$ & & & & & \\
\hline $\begin{array}{l}\text { 14. Analyzing customers data can help in } \\
\text { predicting the behavior of the customers }\end{array}$ & & & & & \\
\hline $\begin{array}{l}\text { 15. Analyzing data requires classification of the } \\
\text { composed data }\end{array}$ & & & & & \\
\hline $\begin{array}{l}\text { 16. The analysis of customer data contributes to } \\
\text { building knowledge of customer }\end{array}$ & & & & & \\
\hline $\begin{array}{l}\text { 17. Company must employ advertising fol } \\
\text { acquiring new customers }\end{array}$ & & & & & \\
\hline $\begin{array}{l}\text { 18. Your organization adopts certain techniques } \\
\text { for acquiring new customers }\end{array}$ & & & & & \\
\hline $\begin{array}{l}\text { 19. Marketing communication tools are used for } \\
\text { acquiring new customers }\end{array}$ & & & & & \\
\hline 20. Organization uses customer profiling & & & & & \\
\hline
\end{tabular}

